\title{
Review Article \\ Clinical Applications of Anterior Segment Optical Coherence Tomography
}

\author{
Su-Ho Lim ${ }^{1,2}$ \\ ${ }^{1}$ Department of Ophthalmology, Yeungnam University College of Medicine, Daegu, Republic of Korea \\ ${ }^{2}$ Department of Ophthalmology, Daegu Veterans Health Service Medical Center, 60 Wolgok-ro, Dalseo-Gu, Daegu 704-802, Republic \\ of Korea
}

Correspondence should be addressed to Su-Ho Lim; mdshlim@gmail.com

Received 20 December 2014; Accepted 21 February 2015

Academic Editor: Edward Manche

Copyright (C) 2015 Su-Ho Lim. This is an open access article distributed under the Creative Commons Attribution License, which permits unrestricted use, distribution, and reproduction in any medium, provided the original work is properly cited.

Anterior segment optical coherence tomography (AS-OCT) was recently developed and has become a crucial tool in clinical practice. AS-OCT is a noncontact imaging device that provides the detailed structure of the anterior part of the eyes. In this review, the author will discuss the various clinical applications of AS-OCT, such as the normal findings, tear meniscus measurement, ocular surface disease (e.g., pterygium, pinguecula, and scleromalacia), architectural analysis after cataract surgery, post-LASIK keratectasia, Descemet's membrane detachment, evaluation of corneal graft after keratoplasty, corneal deposits (corneal dystrophies and corneal verticillata), keratitis, anterior segment tumors, and glaucoma evaluation (angle assessment, morphological analysis of the filtering bleb after trabeculectomy, or glaucoma drainage device implantation surgery). The author also presents some interesting cases demonstrated via AS-OCT.

\section{Introduction}

Optical coherence tomography (OCT) is a noncontact optical device that provides cross-sectional images and quantitative analysis of the ocular tissues, mainly the posterior segment [1]. In 1994, Izatt et al. [2] presented the first report of the OCT image of the corneal and anterior segment. Anteriorsegment OCT (AS-OCT) has become a crucial tool in clinical practice. In this review, the author discussed the various clinical applications of AS-OCT and its limitations.

\section{Devices and Normal Findings}

Anterior-segment OCT systems are categorized by wavelength of light sources; dedicated systems using $1310 \mathrm{~nm}$ (Zeiss Visante, Heidelberg SL-OCT, Tomey CASIA, etc.) and systems converted from a retinal scanner using $830 \mathrm{~nm}$ (Optovue RTvue, Optovue iVue, Zeiss Cirrus, Heidelberg Spectralis, etc.) [3]. Due to the different light sources, there are some differences between the two groups. A shorterwavelength $(830 \mathrm{~nm}$, near infrared) system provides a higher axial resolution, but its imaging depth is limited. On the contrary, a longer-wavelength system provides deeper penetration, and a $1310 \mathrm{~nm}$ wavelength is strongly absorbed by water in ocular media, and as such, a small amount of the light reaches the retina.

Figure 1 shows the horizontal OCT section of the normal cornea using frame-averaged images. The ophthalmologist can distinguish a highly reflective tear film over epithelium (a), Bowman's layer (b), corneal stroma layer (c), Descemet's membrane (d), and endothelium (e).

\section{Tear Meniscus Measurement}

Tear film instability with potential damage of the ocular surface is an important concept in relation to the dry-eye syndrome [4]. Majority of the conventional tests, however, including the Schirmer test or staining, have the disadvantage of invasiveness, which influences the results [5]. Thus, various modalities have been investigated to evaluate the tear film, including AS-OCT.

Tear meniscus measurement via AS-OCT seems to be effective for the quantitative tear evaluation and diagnosis of the dry-eye syndrome or of patients with excessive tearing 


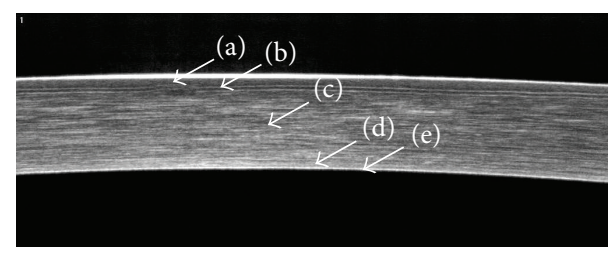

FIGURE 1: Horizontal OCT section of the normal cornea: epithelium (a), Bowman's layer (b), corneal stroma layer (c), Descemet's membrane (d), and endothelium (e).

with punctal stenosis [5-7]. Tear meniscus measurement was recommended for taking an image immediately after blinking, and three parameters were usually measured: the tear meniscus height (TMH), tear meniscus depth (TMD), and tear meniscus area (TMA) [5] (Figure 2). Sizmaz et al. [8] reported that the tear meniscus height was lower in the patients with Grave's diseases compared to the normal control, which suggests that the tear function is significantly disturbed in Grave's diseases.

After the installation of an artificial tear [7] or punctal occlusion [9], AS-OCT was able to quantify a dramatic increase in tear meniscus. On the contrary, the tear meniscus height was decreased after the four-snip punctoplasty procedure [6] or dacryocystorhinostomy in the patients with epiphora [10]. In summary, OCT can be a valuable noninvasive and quick clinical tool for the evaluation of a tear film [9].

\section{Pterygia, Pinguecula, and Scleromalacia after Surgery}

AS-OCT can provide high-resolution images of the anatomical relationship between the corneal tissues and pterygium and the pinguecula [11-13]. Soliman and Mohamed [11] reported that the primary pterygium revealed the elevation of the corneal epithelium by a wedge-shaped mass separating the epithelium from the underlying Bowman's membrane (Figures 3(a) and 3(b)). The image of the pseudopterygium showed that the overgrowing membrane was not really attached to the underlying cornea (Figure 3(c)). On the contrary, the OCT images of the pinguecula stopped at the limbal area (Figure 3(d)) [11]. The quantitative data obtained via ASOCT also allow the accurate evaluation of the conjunctival changes over time after pterygium surgery with conjunctival autograft [14] and argon photocoagulation of the pinguecula [12].

Besides the results of the previous studies [11-14], the interpretation of the AS-OCT may be helpful for predicting the residual corneal opacity after surgery and the difficulty during tissue dissection (Figures 3(a) and 3(c)). Moreover, the scleral thinning or scleromalacia after surgery can be repaired using a preserved scleral graft with or without amnioticmembrane transplantation [15]. Fortunately, with the aid of AS-OCT, the surgeon can consider the residual stromal-bed thickness and can estimate the graft thickness when planning surgery such as lamellar scleral graft or amniotic-membrane transplantation (Figure 4).

\section{Architectural Analysis of Cataract Surgery: Cornea, Lens, and Biometry}

AS-OCT was also used to image the clear corneal incision after cataract surgery [16-18]. On OCT, radial scans may be performed at the corneal incision site to analyze the following parameters: the curvilinear length (the total length between the internal and external wound openings), the linear length (the line between the internal and external wound openings), the angle between the corneal surface tangents, the architectural deformation, and the external depth of the incision [17]. In particular, the OCT image after cataract extraction can show the detailed wound architecture, including the plane of incision, Descemet's membrane detachment (DMD), endothelial misalignment, loss of coaptation, and endothelial or epithelium gaping (Figure 5).

With regard to the complications, the microaxial cataract surgery group had slightly fewer undesirable effects on the incision site compared to the biaxial group [16], and the femtosecond-laser-generated corneal incision had a significantly lower endothelial gaping and endothelial misalignment compared to keratome incision [18].

Recently, Nagy et al. [19] reported that AS-OCT imaging was able to detect the tissue changes within the lens after femtosecond laser capsulorhexis and nuclear fragmentation, and there was a case report demonstrating posterior capsular rent in posterior polar cataract detected via AS-OCT [20]. In vivo three-dimensional (3D) biometry before and after cataract surgery was reported by Ortiz and colleagues [21].

In conclusion, AS-OCT provides sufficient information on the wound architecture and the biometric parameters, and thus surgeons can consider the structural stability of the cataract wound incision and can monitor the occurrence of complications.

\section{Refractive Surgery and Ectatic Disorders}

Keratectasia is a significant concern for refractive surgery. Therefore, many refractive surgeons have tried to minimize the incidence of post-LASIK ectasia. The ectasia risk factor score system provides a screening strategy to help minimize the risk and suggested that abnormal topography (forme fruste keratoconus), residual stromal-bed thickness, age, and preoperative corneal thickness are important factors [22]. The recommended residual stromal-bed thickness is $250-325 \mu \mathrm{m}$ $[22,23]$.

High-resolution OCT is helpful in the visualization of flap thickness, flap interface (flap-stroma relationship), and flap displacement [24]. Reinstein et al. [25] reported that the residual stromal thickness measured via OCT was thicker than that measured through very high-frequency ultrasound in many eyes with insufficient residual stromal thickness. Zhang et al. [26] demonstrated that flaps creased by femtosecond laser were more accurate, reproducible, and uniform compared to those creased by microkeratome. Timing for checking the LASIK flap thickness is also important. At one week, the surgically induced corneal changes were mostly resolved, and the interface can be easily seen via OCT. Thus, 


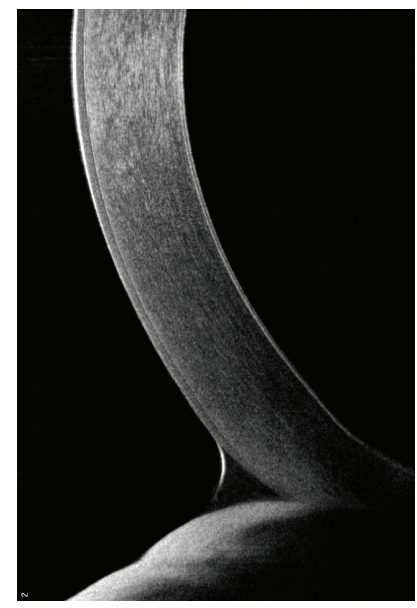

(a)

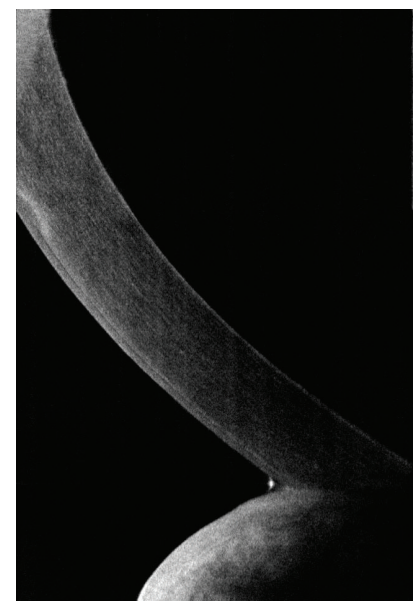

(b)

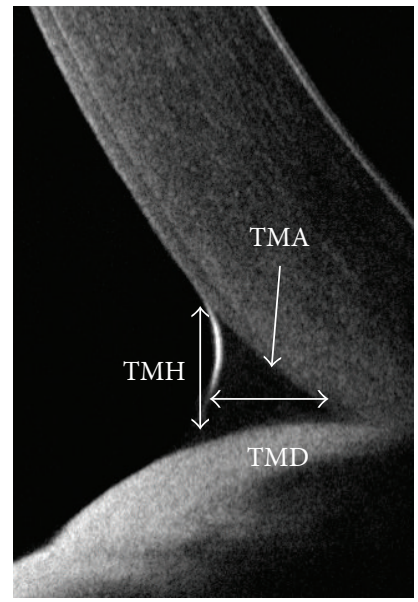

(c)

FIGURE 2: Tear meniscus measurement by AS-OCT. Normal (a), dry eye syndrome (b), three parameters that were usually measured (c); tear meniscus height (TMH), tear meniscus depth (TMD), and tear meniscus area (TMA).

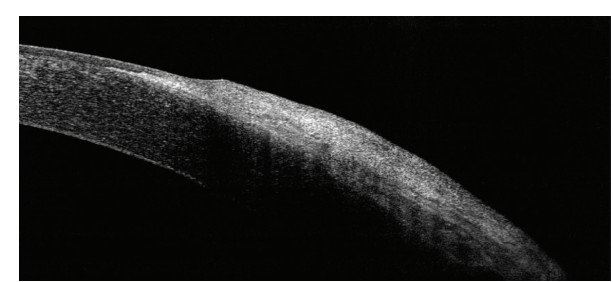

(a)

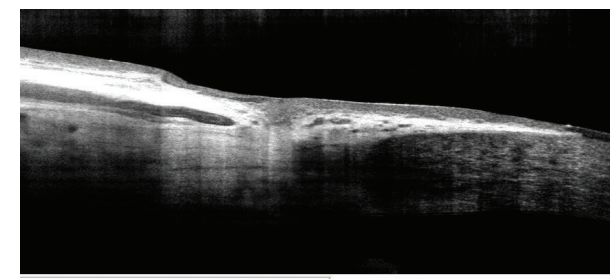

(c)

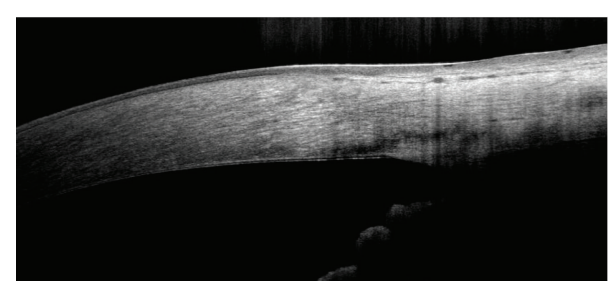

(b)

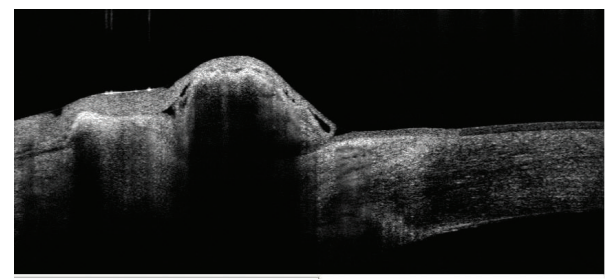

(d)

FIGURE 3: AS-OCT images of pterygium and pinguecula. Pterygium with corneal opacity (a), pterygium without corneal opacity (b), pseudopterygium (c), and pinguecula (d).

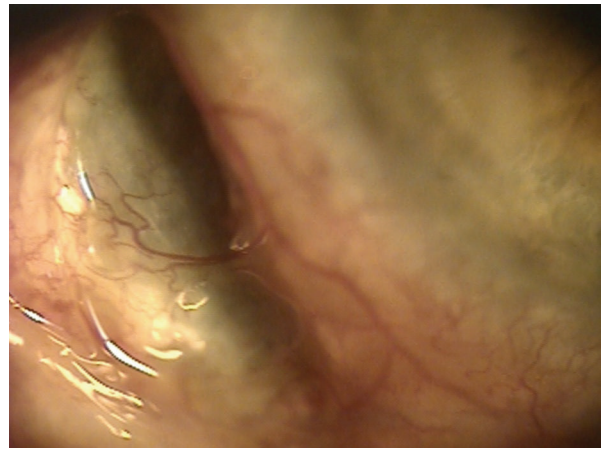

(a)

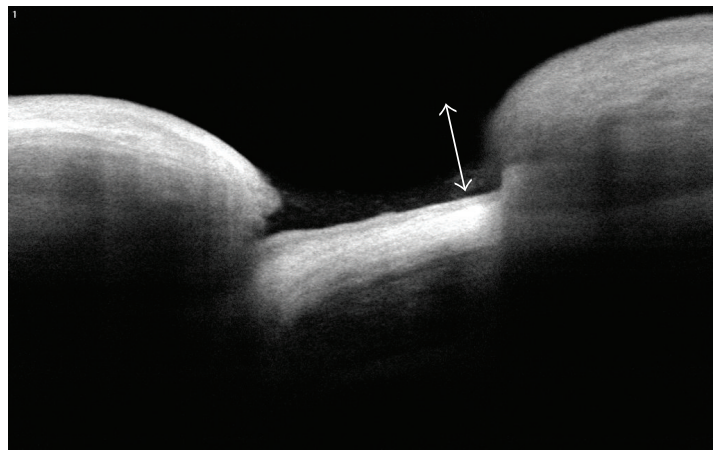

(b)

FIGURE 4: Anterior segment photography (a) and OCT image (b) of scleral thinning after surgery. 


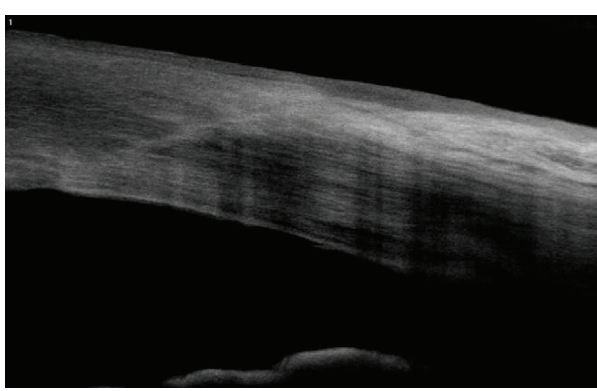

(a)

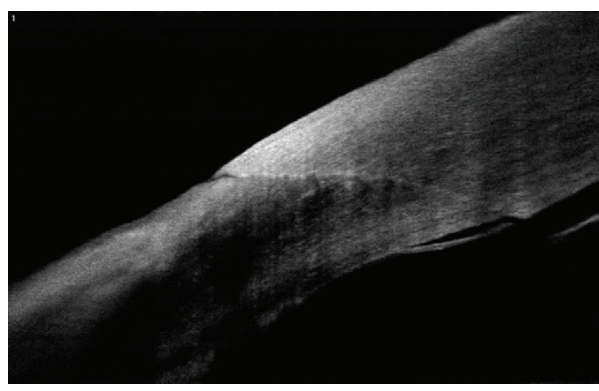

(c)

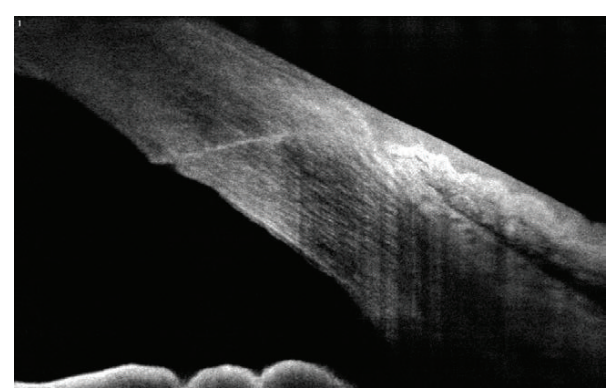

(b)

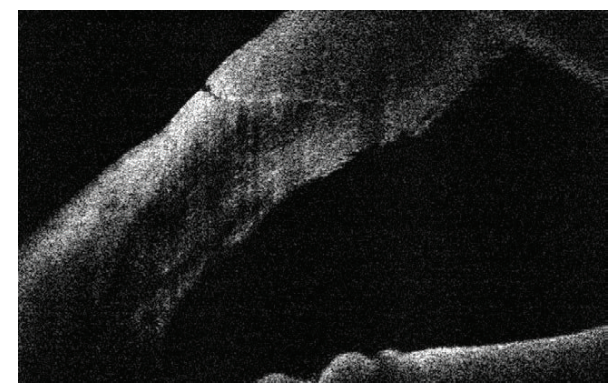

(d)

Figure 5: Architectural analysis of cataract surgery. Well apposed corneal wound (1 plane) (a), loss of cooptation with minimal endothelial misalignment ( 2 plane) (b), minimal Descemet's membrane detachment with epithelial gap (2 plane) (c), and loss of cooptation with endothelial gap (3 plane) (d).

Li et al. [27] suggested that this time is best for measuring the flap thickness.

The detection of an ectatic change also has clinical pitfalls. Li et al. [28] provided several parameters for detecting the asymmetry and global or focal thinning, as follows: (1) I-S (the difference between the average thickness of the inferior octant and that of the superior octant) $>31 \mu \mathrm{m}$; (2) IT-SN (the difference between the inferotemporal octant and the superonasal octant) $>48 \mu \mathrm{m}$; (3) minimum <492 $\mu \mathrm{m}$; (4) minimum-maximum $<-63 \mu \mathrm{m}$; and (5) the thinnest region of the cornea is located outside the central $2 \mathrm{~mm}$ area. They suggested that one abnormal parameter provides suspect keratoconus, and two or more abnormal parameters provide a definite diagnosis (Figure 6).

The qualitative and quantitative evaluation of the cornea via AS-OCT before implantation of the intrastromal ring segment may offer safer surgery [29].

Corneal collagen cross-linking (CXL) has emerged as a promising technique to increase corneal stiffness and stabilize the ectatic corneal leading to inhibition of progression for keratoconus and postoperative LASIK ectasia [30]. A corneal stromal demarcation line indicates the transition zone (at a depth of approximately $300 \mu \mathrm{m}$ ) between the cross-linked anterior corneal stroma and the untreated posterior stroma after CXL [30-33]. AS-OCT can visualize the demarcation line as hyperreflective line and evaluate the depth of the line which is correlated with the effective depth of the CXL treatment [31-33]. In recent comparative study, both confocal microscopy and AS-OCT have similar results in evaluating the depth of corneal demarcation line after CXL (confocal 306.2 $\mu \mathrm{m}$ versus AS-OCT $300.7 \mu \mathrm{m}$ ) [31]. Yam et al. measured demarcation line using AS-OCT and showed that it may decrease with the severity of ectasia and age [32]. And the mean depth measured by AS-OCT after CXL treatment is greater centrally in comparison to nasal and temporal depths $(310.7 \mu \mathrm{m}$ centrally, $212.1 \mu \mathrm{m}$ nasally, and $218.0 \mu \mathrm{m}$ temporally) [33]. In summary, AS-OCT may also provide sufficient monitoring of the depth of the corneal demarcation after CXL as with confocal microscopy.

\section{Assessment of Descemet's Membrane: Descemet's Membrane Detachment and Keratoplasty}

Descemet's membrane detachment (DMD) is considered a severe complication after intraocular surgery and trauma $[34,35]$. Some DMDs, however, reattach spontaneously with a good prognosis, and a few corneas do not clear in spite of surgical treatment [31]. AS-OCT can demonstrate different statuses of the DMD, including planar/nonplanar, local/extensive detachment, and rupture [34-36]. AS-OCT is also a valuable tool for selecting the appropriate treatment and for monitoring the treatment outcomes when corneal edema is present [35] (Figure 7).

AS-OCT can also provide detailed information on the cornea after various keratoplasty operations, including penetrating keratoplasty (PKP), Descemet's membrane endothelial keratoplasty (DMEK), and Descemet's membrane stripping automated endothelial keratoplasty (DSAEK). The previous study [37] suggested that AS-OCT is an effective tool for the detection of an early graft detachment after DMEK, to determine if secondary intervention is indicated or is to be 


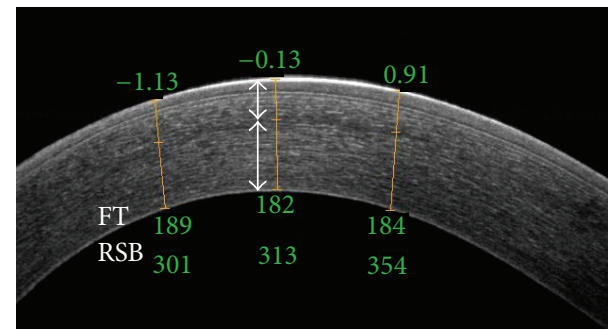

(a)

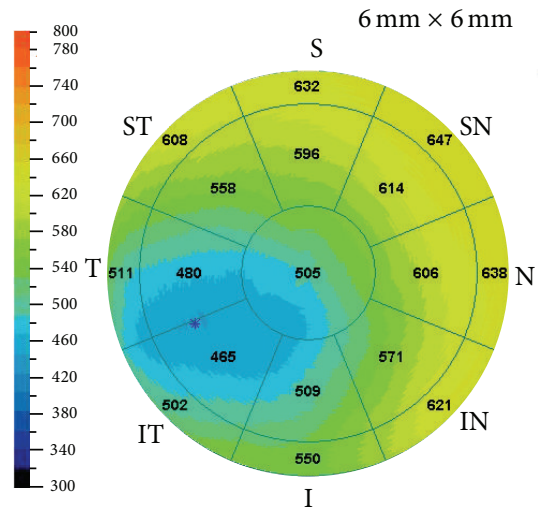

(b)

Pachymetry

Pachymetry statistics within central $5 \mathrm{~mm}$ zone

SN-IT(2-5 mm): 14

Min:

Min-median:

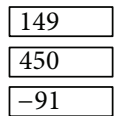

$\mathrm{SN}-\mathrm{I}(2-5 \mathrm{~mm}): 87$

Location $Y$ :

Min-max: -191

Min thickness at $(-1.668 \mathrm{~mm},-0.760 \mathrm{~mm})$ indicated as *

(c)

FIGURE 6: AS-OCT image of post-LASIK keratectasia. Horizontal OCT section demonstrating flap thickness (FT) and residual stromal bed thickness (RSB) (a), pachymetry map (b), and asymmetry parameters (c).
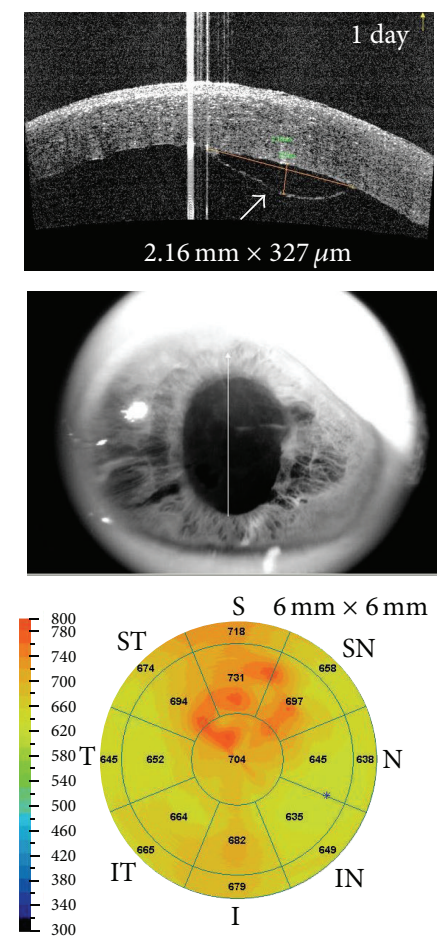

(a)
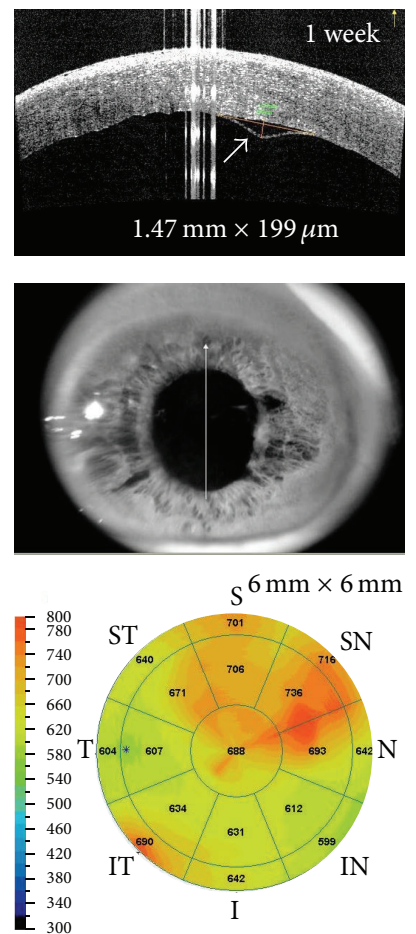

(b)
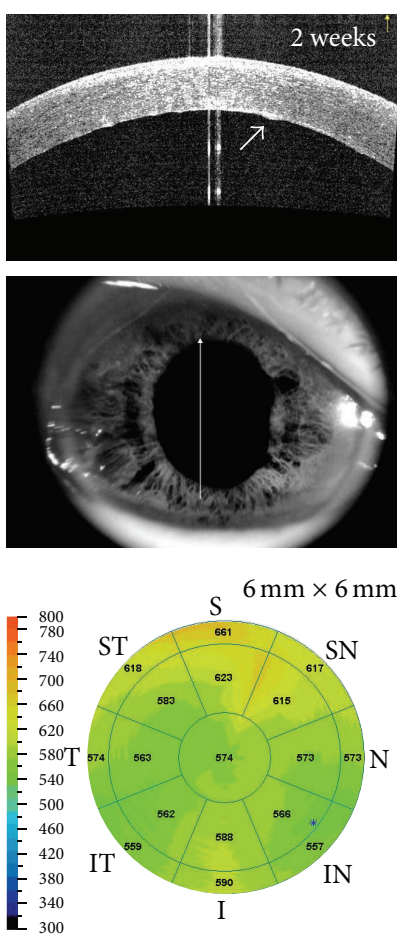

(c)

FIGURE 7: Spontaneous resolution of a detachment of Descemet's membrane following phacoemulsification. Optical coherence tomography (OCT) images at 1 day after cataract surgery (a) demonstrated superior planar type DMD with diffuse corneal edema. OCT images at postoperative 1 week (b) and 2 weeks (c) revealed spontaneous resolution of DMD without descemetopexy. 
avoided. Yeh et al. [38] also reported that the one-hour ASOCT scan showed the best predictive value of the six-month graft adherence status after DMEK.

The wound interface pattern can be shown by AS-OCT during DSAEK [36] or after PKP. Miyakoshi et al. [39] suggested that AS-OCT is useful for detecting the interface fluid between the host cornea and the graft during a DSAEK. Similarly, Sung and Yoon [40] showed that the alignment pattern of the wound interface after PKP differed according to the clinical diagnosis before surgery.

\section{Explanatory Text, Figure 7}

A 84-year-old male patient with benign prostate hypertrophy had underwent cataract surgery. During phacoemulsification, posterior capsular rupture was occurred because of severe intraoperative floppy iris syndrome. Thus, sulcus placement of single-piece acrylic IOL with anterior vitrectomy was performed.

On 1 day after surgery, slit-lamp examination revealed diffuse stromal and epithelial edema (central corneal thickness, CCT $704 \mu \mathrm{m}$ ). Optical coherence tomography (OCT) demonstrated superior Descemet's membrane detachment (DMD, base $\times$ height, $2.16 \mathrm{~mm} \times 327 \mu \mathrm{m}$ ) and stromal thickening. The uncorrected visual acuity (UCVA) was 20/200 with no pinhole improvement and IOP was $14 \mathrm{mmHg}$. However, he deferred intracameral gas injection.

On postoperative 1 week, slit-lamp and OCT showed partial resolution of $\operatorname{DMD}(1.47 \mathrm{~mm} \times 199 \mu \mathrm{m})$. On two weeks after surgery, slit-lamp and OCT displayed uniform attachment of the DMD without any folds or gaps between Descemet's membrane and corneal stroma (CCT $574 \mu \mathrm{m}$ ). The UCVA was improved to $20 / 32$.

\section{Corneal Deposits: Corneal Dystrophies and Corneal Verticillata (En-Face OCT)}

When corneal opacities obscure the clinical differentiation between the anterior and deep infiltrates, OCT may determine the layers of the accumulation [41]. OCT measurement was reported to be highly repeatable: $2.1 \mu \mathrm{m}$ centrally and $1.2 \mu \mathrm{m}$ pericentrally [42]. Thus, AS-OCT provides useful information for the selection and planning depth of surgical procedures such as phototherapeutic keratectomy for removing corneal opacities with granular corneal dystrophy $[43,44]$ (Figure 8).

Other corneal deposits can also be demonstrated by AS-OCT. To the best of the authors' knowledge, there has been no case report with amiodarone-induced keratopathy demonstrated by AS-OCT. In a previous study with in vivo confocal microscopy [45], there were highly reflective and bright intracellular inclusions in the epithelial layers, and these findings were more evident within the basal cell layer in the patients with amiodarone keratopathy [44-46]. Some OCT machines can provide particular scan modes, such as en-face scan, which offers a new view of the different layers of tissue, like confocal microscopy [47]. In this patient, highly reflective and bright intracellular inclusions were observed
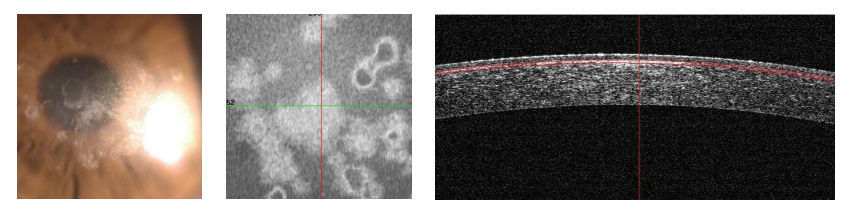

(a)
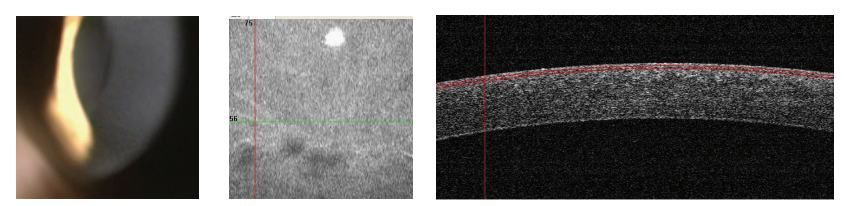

(b)

FIGURE 8: Anterior segment photography. En-face and horizontal OCT images of corneal deposits. Granular corneal dystrophy (a) and corneal verticillata (b).

mainly in the epithelial basal layer, and cornea verticillata was also detected easily in AS-OCT (en-face view) compared to the conventional slit lamp examination (Figure 8).

\section{Keratitis}

In clinical situations, the necrotic lesion and area of infiltration are not usually clear in microbial keratitis. Thus, it is easy for the cornea perforation and resection to become incomplete, and the recurrence of keratitis in severe cases needed surgical intervention [48]. Fortunately, the use of OCT allows the objective measurement of the corneal thickness and is an additional method for following microbial keratitis with greater accuracy compared to biomicroscopy alone [49]. Soliman et al. [50] reported that fungal keratitis grasped two unique patterns of early localized and diffuse necrotic stromal cystic spaces. Sun et al. [48] suggested that the removal of the necrotic tissue combined with conjunctival flap under the guidance of AS-OCT in the treatment of fungal keratitis is a safe and effective method. Similar to a previous report [49], in HSV keratitis with underlying granular corneal dystrophy, AS-OCT allowed the precise localization of microcystic edema and keratic precipitate in the subject patient (Figure 9).

\section{Tumors}

AS-OCT is a relatively reliable, convenient, and noncontact method for detecting and measuring anterior-segment tumors [51]. Image analysis [52] comparing UBM and ASOCT with 200 patients, however, revealed the adequate visualization of all tumor margins (95\% versus $40 \%$ ), posterior tumor shadowing (5\% versus $72 \%$ ), and high overall image quality ( $80 \%$ versus $68 \%$ ). UBM showed a better resolution for a pigmented tumor (66\% versus $34 \%$ ) and nonpigmented tumors (61\% versus $39 \%)$. In another study comparing OCT to $\mathrm{UBM}$ in a nonpigmented iris tumor, the images of the anterior tumor surface and internal tumor heterogeneity were equivalent, but the posterior tumor surface was well defined in $54 \%$ of the OCT images versus $100 \%$ of the UBM 

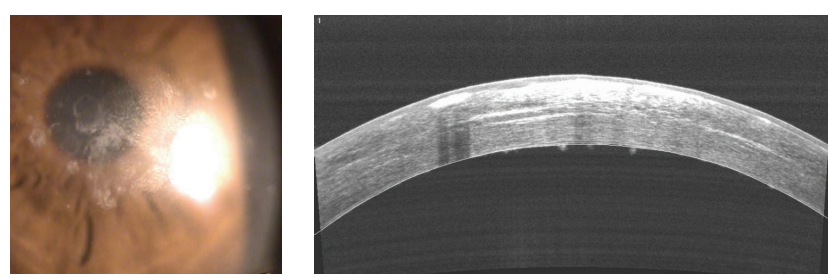

(a)
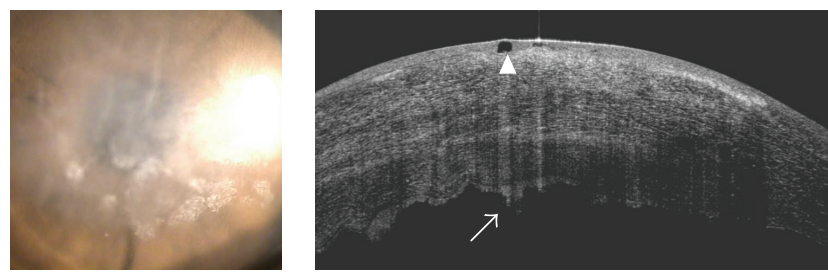

(b)

FIGURE 9: Herpetic keratitis with granular corneal dystrophy. In HSV keratitis with underlying granular corneal dystrophy, AS-OCT images (b) allowed the precise localization of microcystic edema (arrow head) and keratic precipitate (arrow) compared to baseline (a).

images [53]. In conclusion, UBM showed the superior image quality and reproducibility of the anterior-segment tumor. Nevertheless, OCT is a noncontact, noninvasive technique that can be employed for supplementary examination in some selected nonpigmented tumors. Figure 10 demonstrates that the OCT image showed a relative good anterior tumor surface, but the posterior tumor surface was not seen, like in the previous studies $[52,53]$.

\section{Glaucoma: Angle Assessment and Laser Iridotomy}

Gonioscopy is a gold-standard method for measuring the anterior chamber angle (ACA), but it is a subjective contact method with poor reproducibility and requires an experienced examination technique. On the contrary, AS-OCT can be performed easily, with relative good repeatability and reproducibility [54]. AS-OCT also provides several parameters about angle assessment [55-57]: ACA, angle opening distance (AOD 500 and $750 \mu \mathrm{m}$ ), and trabecular-iris space area (TISA). One study suggests that AOD750 is the most useful angle measurement tool for identifying a narrow angle in AS-OCT images [58].

Fourier domain OCT (FD-OCT), however, had limited visualizations for the ciliary sulcus and posterior border of the ciliary body in most of the cases because the iris pigment epithelium is not transparent with regard to infrared light, and poor definition of the scleral spur was also reported in approximately $25 \%$ of AS-OCT images [58] (Figure 11 ). Despite these disadvantages, OCT had additional merits, such as a noncontact-type performance without an artificial opening of the angle.

Angle assessment for glaucoma may be widely applicable in clinical situations: screening for angle closure [58], evaluation of the structural cause (including plateau iris configuration, pupillary block, and malignant glaucoma), evaluation of the efficacy of a laser procedure $[56,57]$ (patency, angle change, and concavity), and dynamic analysis of the iris configuration [59]. In the aspect of treatment outcomes, Lee et al. [57] reported that the ACA parameters changed significantly after laser iridotomy, but ACA remained unchanged in some narrow-angle eyes despite iridotomy.

Concerning the safety profile, laser iridotomy is a relatively safe procedure, but there is still a potential risk of corneal endothelial damage. Many proposed mechanisms were hypothesized: direct focal injury, thermal damage, mechanical shock wave, iris pigment dispersion, transientraised intraocular pressure, inflammation, and breakdown of the blood-aqueous barrier [60]. To the best of the author's knowledge, however, there has been no case report of endothelial damage demonstrated by AS-OCT. The author presents a case with stromal damage and thickened Descemet's membrane accompanying endothelial damage after laser iridotomy (Figure 11).

Although angle assessment via AS-OCT was shown to have poor quality compared with UBM, AS-OCT may be helpful in various clinical situations in glaucoma patients because of its noncontact nature.

\section{Glaucoma: Assessment of the Filtering Bleb and Tube}

Although OCT was not developed to evaluate the filtering bleb, AS-OCT can visualize filtering blebs and can reveal the details of their morphology (Figure 12) [61]. Many articles have described the association of the bleb morphology and IOP control. Nakano et al. [62] predicted bleb failure based on the bleb wall uniformity in developing bleb after trabeculectomy. They reported that the multiple-layer appearance had a good bleb function after six months. Tominaga et al. [63] also stated that the low-reflectivity wall and the presence of episcleral fluid were associated with good IOP controls after trabeculectomy. Pfenninger et al. [64] demonstrated the correlation between the internal reflectivity of the fluid-filled cavity and IOP control after the recent trabeculectomy. The AS-OCT results, however, revealed no significant association between reflectivity and IOP control in Ahmed glaucoma valve (AGV) surgeries, and the maximum bleb wall was thinner in the surgical success group compared with the surgical failure group [65]. Recently, the 3D AS-OCT technique allows a detailed evaluation of the internal morphology of filtering blebs and precise identification of the filtration opening on the scleral flap margin after trabeculectomy [66].

In a clinical situation, AS-OCT was applicable for determining which blebs were suitable for needling [67] and which could be used to evaluate the bleb change after laser suture lysis [68]. Moreover, it provided detailed information when planning bleb revision surgery for overhanging filtering bleb [69]. In author's opinion, AS-OCT may also be helpful for distinguishing the "real" tube erosion of glaucoma implant surgery because of its noncontact nature (Figure 13).

In summary, the bleb wall anatomy is well assessed by ASOCT while UBM is superior in evaluating a deep structure. 


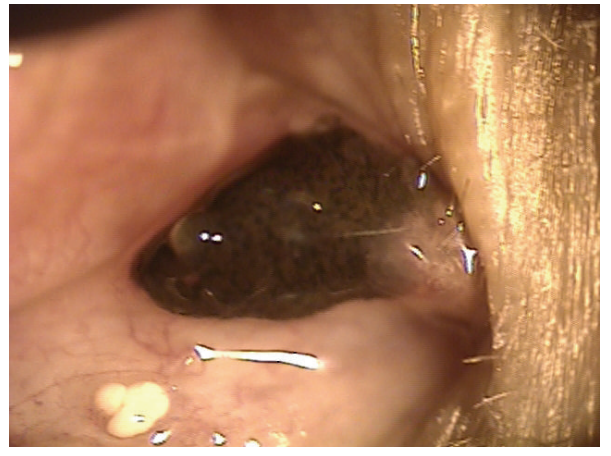

(a)

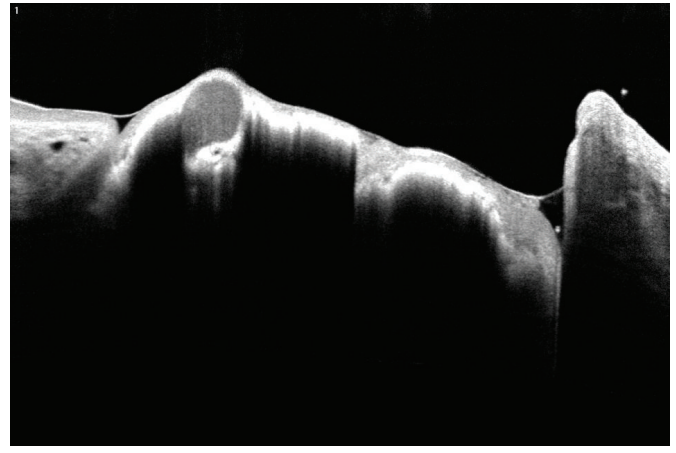

(b)

FIGURE 10: Anterior segment photography (a) and OCT image (b) of conjunctival tumor (nevus).

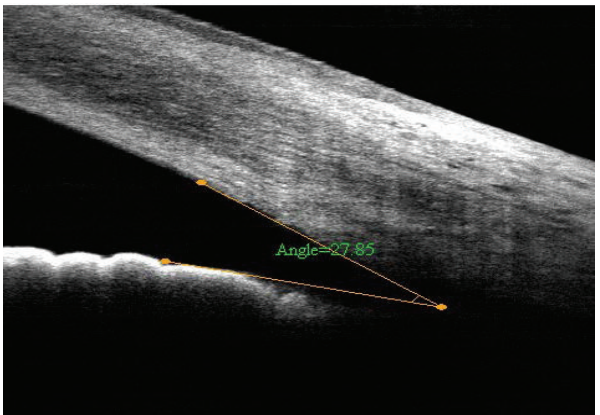

(a)

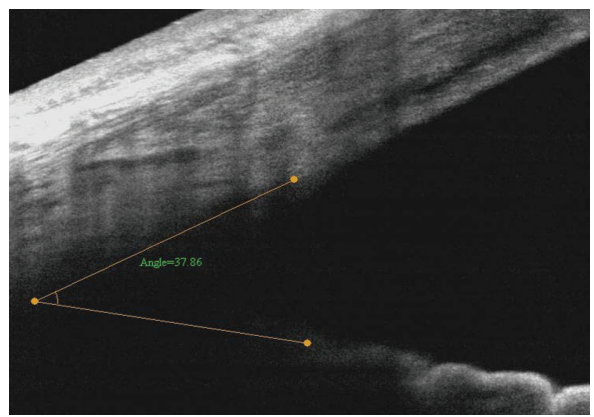

(c)

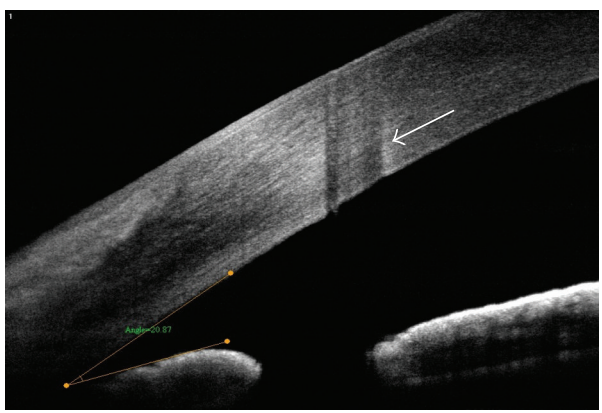

(e)

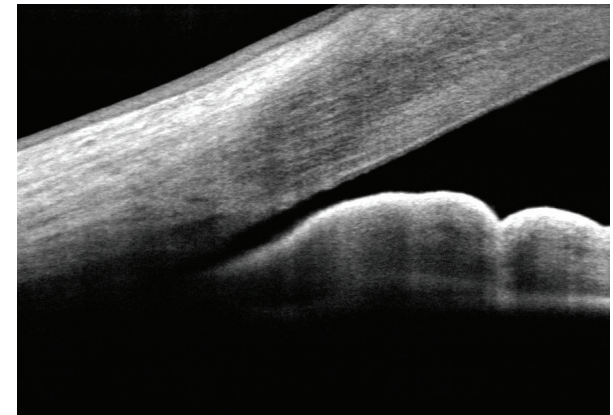

(b)

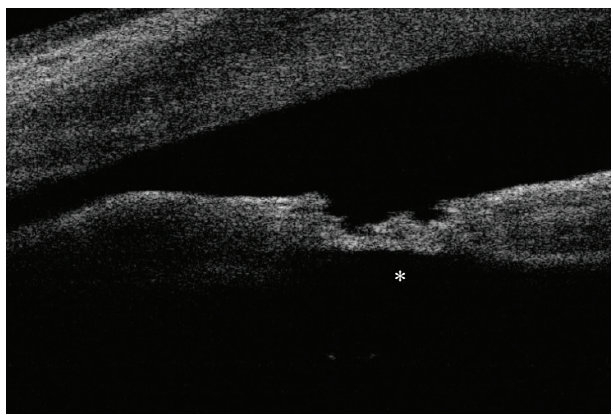

(d)

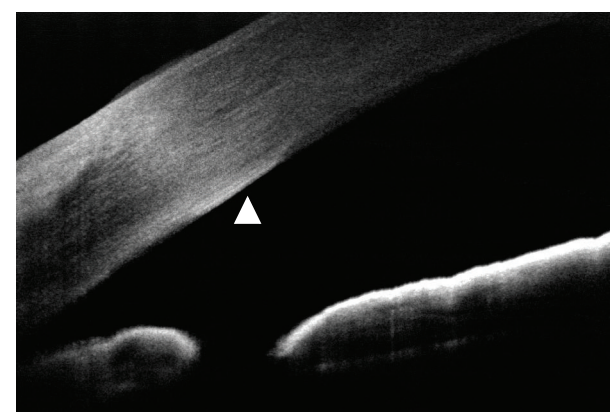

(f)

FIgURE 11: Angle assessment by AS-OCT. Narrow occludable angle (a), plateau iris configuration (b), open angle (c), incomplete laser iridotomy (d), stromal damage (e), and thickened Descemet's membrane after laser iridotomy (f). 

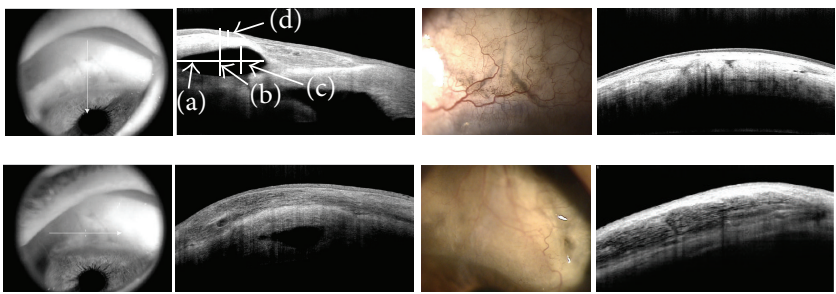

FIGURE 12: Anterior segment OCT images after trabeculectomies. Vertical and horizontal OCT sections (left column) demonstrate various parameters: internal cavity extent (a), bleb height (b), internal cavity height (c), and bleb wall thickness (d). Right upper images demonstrate thick bleb wall and high internal reflectivity suggesting bleb failure. Right lower images demonstrate relatively thin bleb wall and multiplelayer appearance with low internal reflectivity with good IOP control.

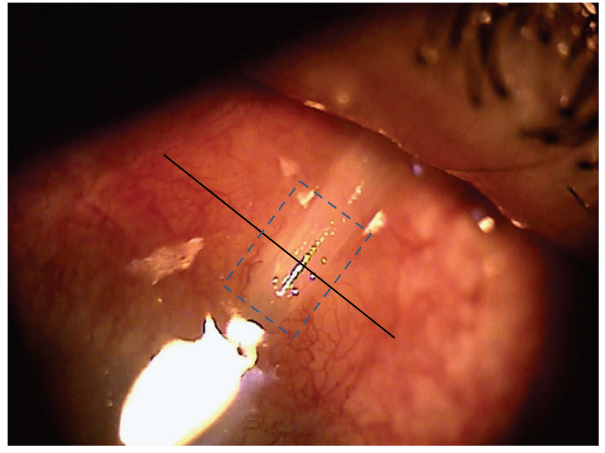

(a)

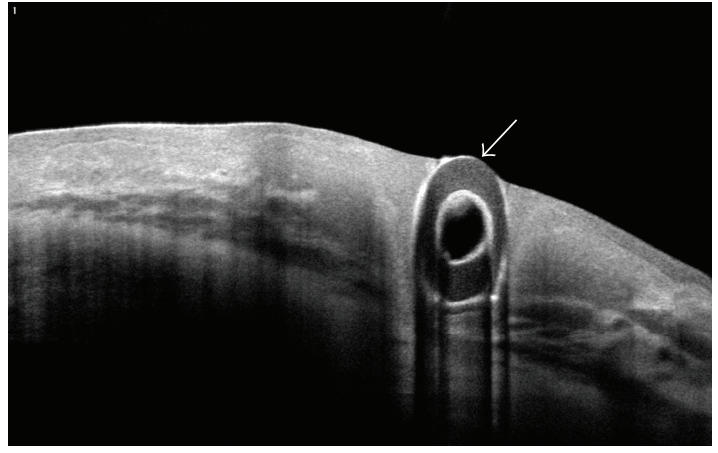

(b)

FIGURE 13: Tube erosion of glaucoma drainage device. Anterior segment optical coherence tomography image. Slit lamp examination revealed an extruded tube of glaucoma drainage device (GDD, Ahmed valve) with melting of scleral patch and conjunctival erosion. (a) Anterior segment optical coherence tomography (OCT) also displayed the GDD tube extrusion and loss of overlying conjunctiva (b).

Particularly, AS-OCT can be widely used in the early postoperative stage because of its noncontact characteristics [70].

\section{Explanatory Text, Figure 13}

A 64-year-old male with neovascular glaucoma secondary to proliferative diabetic retinopathy underwent glaucoma drainage device (GDD) implantation in his right eye. Insertion of an Ahmed glaucoma valve (Model FP7, New World Medical Inc., Rancho Cucamonga, CA) with a $4 \times 4 \mathrm{~mm}$ sized overlying scleral patch graft was performed through a fornixbased conjunctiva approach.

Twelve months after surgery, overlying scleral patch graft was not visible. And three months later, he visited the author's clinic due to foreign body sensation, redness, and mild ocular tenderness for several days.

Slit-lamp examination demonstrated an extruded tube with melting of scleral patch (blue box) and conjunctival erosion. AS-OCT also showed the loss of conjunctival tissue overlying GDD tube. Arrow indicated the hyperreflective tear film on extruded tube. To the best of the author's knowledge, this is first photographic report on tube erosion of GDD demonstrated by AS-OCT.

\section{Conclusions}

In summary, AS-OCT can be widely applicable in various clinical diseases, including tear meniscus evaluation, ocular-surface disease, corneal dystrophies and stromal diseases, tissue change analysis after cataract and glaucoma surgery, and angle assessment. This noncontact-type technology with a high resolution and high reproducibility provides comprehensive and quantitative information.

\section{Consent}

All ophthalmic images in this paper were obtained from the Department of Ophthalmology, Daegu Veterans Health Service Medical Center. Written informed consents were obtained from all patients for publication of this paper and any accompanying images.

\section{Conflict of Interests}

The author does not have a proprietary interest in the study or financial interests to disclose.

\section{References}

[1] J. L. B. Ramos, Y. Li, and D. Huang, "Clinical and research applications of anterior segment optical coherence tomography-a review," Clinical and Experimental Ophthalmology, vol. 37, no. 1, pp. 81-89, 2009.

[2] J. A. Izatt, M. R. Hee, E. A. Swanson et al., "Micrometer-scale resolution imaging of the anterior eye in vivo with optical 
coherence tomography," Archives of Ophthalmology, vol. 112, no. 12, pp. 1584-1589, 1994.

[3] D. Huang, "Anterior segment optical coherence tomography," in Proceedings of the American Academy of Ophthalmology Annual Meeting, pp. 1-28, New Orleans, La, USA, 2013.

[4] "The definition and classification of dry eye disease: report of the definition and classification subcommittee of the international dry eye workShop (2007)," The Ocular Surface, vol. 5, no. 2, pp. 75-92, 2007.

[5] G. Czajkowski, B. J. Kaluzny, A. Laudencka, G. Malukiewicz, and J. J. Kaluzny, "Tear meniscus measurement by spectral optical coherence tomography," Optometry and Vision Science, vol. 89, no. 3, pp. 336-342, 2012.

[6] S. E. Kim, S. J. Lee, S. Y. Lee, and J. S. Yoon, "Outcomes of 4-snip punctoplasty for severe punctal stenosis: measurement of tear meniscus height by optical coherence tomography," American Journal of Ophthalmology, vol. 153, no. 4, pp. 769.e2-773.e2, 2012.

[7] M. C. Bujak, S. Yiu, X. Zhang, Y. Li, and D. Huang, "Serial measurement of tear meniscus by FD-OCT after instillation of artificial tears in patients with dry eyes," Ophthalmic Surgery Lasers and Imaging, vol. 42, no. 4, pp. 308-313, 2011.

[8] S. Sizmaz, R. Altan-Yaycioglu, O. S. Bakiner, E. Bozkirli, M. Coban-Karatas, and B. Ulas, "Assessment of tear meniscus with optical coherence tomography in thyroid-associated ophtalmopathy," Current Eye Research, vol. 39, no. 4, pp. 323-328, 2014.

[9] O. M. A. Ibrahim, M. Dogru, T. Kojima et al., "OCT assessment of tear meniscus after punctal occlusion in dry eye disease," Optometry and Vision Science, vol. 89, no. 5, pp. E770-E776, 2012.

[10] K. Ohtomo, T. Ueta, R. Fukuda et al., "Tear meniscus volume changes in dacryocystorhinostomy evaluated with quantitative measurement using anterior segment optical coherence tomography," Investigative Ophthalmology and Visual Science, vol. 55, no. 4, pp. 2057-2061, 2014.

[11] W. Soliman and T. A. Mohamed, "Spectral domain anterior segment optical coherence tomography assessment of pterygium and pinguecula," Acta Ophthalmologica, vol. 90, no. 5, pp. 461465, 2012.

[12] S. J. Ahn, K.-H. Shin, M. K. Kim, W. R. Wee, and J. W. Kwon, "One-year outcome of argon laser photocoagulation of pinguecula," Cornea, vol. 32, no. 7, pp. 971-975, 2013.

[13] M. N. Welch, C. D. Reilly, K. Kalwerisky, A. Johnson, and S. G. Waller, "Pterygia measurements are more accurate with anterior segment optical coherence tomography-a Pilot study," Nepalese Journal of Ophthalmology, vol. 3, no. 1, pp. 9-12, 2011.

[14] A. Kheirkhah, M. Adelpour, M. Nikdel, R. Ghaffari, H. Ghassemi, and H. Hashemi, "Evaluation of conjunctival graft thickness after pterygium surgery by anterior segment optical coherence tomography," Current Eye Research, vol. 36, no. 9, pp. 782-786, 2011.

[15] J. H. Oh and J. C. Kim, "Repair of scleromalacia using preserved scleral graft with amniotic membrane transplantation," Cornea, vol. 22, no. 4, pp. 288-293, 2003.

[16] I. Can, H. A. Bayhan, H. Çelik, and B. Bostanci Ceran, "Anterior segment optical coherence tomography evaluation and comparison of main clear corneal incisions in microcoaxial and biaxial cataract surgery," Journal of Cataract and Refractive Surgery, vol. 37, no. 3, pp. 490-500, 2011.

[17] A. Teixeira, C. Salaroli, F. R. Filho et al., "Architectural analysis of clear corneal incision techniques in cataract surgery using
Fourier-domain OCT," Ophthalmic Surgery, Lasers \& Imaging, vol. 43, no. 6, pp. S103-S108, 2012.

[18] D. S. Grewal and S. Basti, "Comparison of morphologic features of clear corneal incisions created with a femtosecond laser or a keratome," Journal of Cataract and Refractive Surgery, vol. 40, no. 4, pp. 521-530, 2014.

[19] Z. Z. Nagy, T. Filkorn, Á. I. Takács et al., "Anterior segment OCT imaging after femtosecond laser cataract surgery," Journal of Refractive Surgery, vol. 29, no. 2, pp. 110-112, 2013.

[20] G. D. Kymionis, V. F. Diakonis, D. A. Liakopoulos, K. I. Tsoulnaras, N. E. Klados, and I. G. Pallikaris, "Anterior segment optical coherence tomography for demonstrating posterior capsular rent in posterior polar cataract," Clinical Ophthalmology, vol. 8, pp. 215-217, 2014.

[21] S. Ortiz, P. Pérez-Merino, S. Durán et al., "Full OCT anterior segment biometry: an application in cataract surgery," Biomedical Optics Express, vol. 4, no. 3, pp. 387-396, 2013.

[22] J. B. Randleman, M. Woodward, M. J. Lynn, and R. D. Stulting, "Risk assessment for ectasia after corneal refractive surgery," Ophthalmology, vol. 115, pp. 37-50, 2008.

[23] I. G. Pallikaris, G. D. Kymionis, and N. I. Astyrakakis, "Corneal ectasia induced by laser in situ keratomileusis," Journal of Cataract and Refractive Surgery, vol. 27, no. 11, pp. 1796-1802, 2001.

[24] C. H. R. Salaroli, Y. Li, and D. Huang, "High-resolution optical coherence tomography visualization of LASIK flap displacement," Journal of Cataract and Refractive Surgery, vol. 35, no. 9, pp. 1640-1642, 2009.

[25] D. Z. Reinstein, T. J. Archer, and M. Gobbe, "Comparison of residual stromal bed thickness measurement among very highfrequency digital ultrasound, intraoperative handheld ultrasound, and optical coherence tomography," Journal of Refractive Surgery, vol. 28, no. 1, pp. 42-47, 2012.

[26] Y. Zhang, Y.-G. Chen, and Y.-J. Xia, “Comparison of corneal flap morphology using AS-OCT in LASIK with the waveLight FS200 femtosecond laser versus a mechanical microkeratome," Journal of Refractive Surgery, vol. 29, no. 5, pp. 320-324, 2013.

[27] Y. Li, M. V. Netto, R. Shekhar, R. R. Krueger, and D. Huang, "A longitudinal study of LASIK flap and stromal thickness with high-speed optical coherence tomography," Ophthalmology, vol. 114, no. 6, pp. 1124.e1-1132.e1, 2007.

[28] Y. Li, D. M. Meisler, M. Tang et al., "Keratoconus diagnosis with optical coherence tomography pachymetry mapping," Ophthalmology, vol. 115, no. 12, pp. 2159-2166, 2008.

[29] R. B. Kucumen, E. Gorgun, N. M. Yenerel, and C. A. Utine, "Intraoperative use of AS-OCT during intrastromal corneal ring segment implantation," Ophthalmic Surgery, Lasers \& Imaging, vol. 43, no. 6, pp. S109-S116, 2012.

[30] G. Wollensak, "Crosslinking treatment of progressive keratoconus: new hope," Current Opinion in Ophthalmology, vol. 17, no. 4, pp. 356-360, 2006.

[31] G. D. Kymionis, M. A. Grentzelos, A. D. Plaka et al., "Correlation of the corneal collagen cross-linking demarcation line using confocal microscopy and anterior segment optical coherence tomography in keratoconic patients," The American Journal of Ophthalmology, vol. 157, no. 1, pp. 110-115, 2014.

[32] J. C. S. Yam, C. W. N. Chan, and A. C. K. Cheng, "Corneal collagen cross-linking demarcation line depth assessed by Visante OCT after CXL for keratoconus and corneal ectasia," Journal of Refractive Surgery, vol. 28, no. 7, pp. 475-481, 2012. 
[33] G. D. Kymionis, M. A. Grentzelos, A. D. Plaka et al., "Evaluation of the corneal collagen cross-linking demarcation line profile using anterior segment optical coherence tomography," Cornea, vol. 32, no. 7, pp. 907-910, 2013.

[34] V. W. S. Chow, T. Agarwal, R. B. Vajpayee, and V. Jhanji, "Update on diagnosis and management of Descemet's membrane detachment," Current Opinion in Ophthalmology, vol. 24, no. 4, pp. 356-361, 2013.

[35] S. Y. Zhou, C. X. Wang, X. Y. Cai, and Y. Z. Liu, "Anterior segment OCT-based diagnosis and management of descemet's membrane detachment," Ophthalmologica, vol. 227, no. 4, pp. 215-222, 2012.

[36] P. Gujar, P. Bhasin, and P. Bhasin, "Bilateral Descemet's membrane detachment after uneventful phacoemulsification in a case of diabetes mellitus," Indian Journal of Ophthalmology, vol. 61, no. 1, pp. 28-29, 2013.

[37] K. Moutsouris, I. Dapena, L. Ham, C. Balachandran, S. Oellerich, and G. R. J. Melles, "Optical coherence tomography, scheimpflug imaging, and slit-lamp biomicroscopy in the early detection of graft detachment after descemet membrane endothelial keratoplasty," Cornea, vol. 30, no. 12, pp. 1369-1375, 2011.

[38] R.-Y. Yeh, R. Quilendrino, F. U. Musa, V. S. Liarakos, I. Dapena, and G. R. J. Melles, "Predictive value of optical coherence tomography in graft attachment after Descemet's membrane endothelial keratoplasty," Ophthalmology, vol. 120, no. 2, pp. 240-245, 2013.

[39] A. Miyakoshi, H. Ozaki, M. Otsuka, and A. Hayashi, "Efficacy of intraoperative anterior segment optical coherence tomography during descemet's stripping automated endothelial keratoplasty," ISRN Ophthalmology, vol. 2014, Article ID 562062, 4 pages, 2014.

[40] M. S. Sung and K. C. Yoon, "Evaluation of graft-host interface after penetrating keratoplasty using anterior segment optical coherence tomography," Japanese Journal of Ophthalmology, vol. 58, no. 3, pp. 282-289, 2014.

[41] C. H. Meyer and W. Sekundo, "Evaluation of granular corneal dystrophy with optical coherent tomography," Cornea, vol. 23, no. 3, pp. 270-271, 2004.

[42] N. M. Samy El Gendy, Y. Li, X. Zhang, and D. Huang, "Repeatability of pachymetric mapping using fourier domain optical coherence tomography in corneas with opacities," Cornea, vol. 31, no. 4, pp. 418-423, 2012.

[43] T.-I. Kim, J. P. Hong, B. J. Ha, R. D. Stulting, and E. K. Kim, "Determination of treatment strategies for granular corneal dystrophy type 2 using Fourier-domain optical coherence tomography," British Journal of Ophthalmology, vol. 94, no. 3, pp. 341-345, 2010.

[44] S. H. Jung, K. E. Han, R. D. Stulting, B. Sgrignoli, T. I. Kim, and E. K. Kim, "Phototherapeutic keratectomy in diffuse stromal haze in granular corneal dystrophy type 2," Cornea, vol. 32, no. 3, pp. 296-300, 2013.

[45] M. Ciancaglini, P. Carpineto, E. Zuppardi, M. Nubile, E. Doronzo, and L. Mastropasqua, "In vivo confocal microscopy of patients with amiodarone-induced keratopathy," Cornea, vol. 20, no. 4, pp. 368-373, 2001.

[46] K. Falke, A. Büttner, M. Schittkowski et al., "The microstructure of cornea verticillata in Fabry disease and amiodaroneinduced keratopathy: a confocal laser-scanning microscopy study," Graefe's Archive for Clinical and Experimental Ophthalmology, vol. 247, no. 4, pp. 523-534, 2009.
[47] M. Alkabes, C. Salinas, L. Vitale, A. Burés-Jelstrup, P. Nucci, and C. Mateo, "En face optical coherence tomography of inner retinal defects after internal limiting membrane peeling for idiopathic macular hole," Investigative Ophthalmology and Visual Science, vol. 52, no. 11, pp. 8349-8355, 2011.

[48] G.-H. Sun, S.-X. Li, H. Gao, W.-B. Zhang, M.-A. Zhang, and W.Y. Shi, "Clinical observation of removal of the necrotic corneal tissue combined with conjunctival flap covering surgery under the guidance of the AS-OCT in treatment of fungal keratitis," International Journal of Ophthalmology, vol. 5, no. 1, pp. 88-91, 2012.

[49] A. Hixson, S. Blanc, and J. Sowka, "Monitoring keratitis resolution with optical coherence tomography," Optometry and Vision Science, vol. 91, no. 4, pp. S40-S45, 2014.

[50] W. Soliman, A. M. Fathalla, D. M. El-Sebaity, and A. K. AlHussaini, "Spectral domain anterior segment optical coherence tomography in microbial keratitis," Graefe's Archive for Clinical and Experimental Ophthalmology, vol. 251, no. 2, pp. 549-553, 2013.

[51] L. Razzaq, K. Emmanouilidis-van der Spek, G. P. M. Luyten, and R. J. W. de Keizer, "Anterior segment imaging for iris melanocytic tumors," European Journal of Ophthalmology, vol. 21, no. 5, pp. 608-614, 2011.

[52] C. Bianciotto, C. L. Shields, J. M. Guzman et al., "Assessment of anterior segment tumors with ultrasound biomicroscopy versus anterior segment optical coherence tomography in 200 cases," Ophthalmology, vol. 118, no. 7, pp. 1297-1302, 2011.

[53] H. Krema, R. A. Santiago, J. E. Gonzalez, and C. J. Pavlin, "Spectral-domain optical coherence tomography versus ultrasound biomicroscopy for imaging of nonpigmented iris tumors," American Journal of Ophthalmology, vol. 156, no. 4, pp. 806-812, 2013.

[54] H. Li, C. K. S. Leung, C. Y. L. Cheung et al., "Repeatability and reproducibility of anterior chamber angle measurement with anterior segment optical coherence tomography," British Journal of Ophthalmology, vol. 91, no. 11, pp. 1490-1492, 2007.

[55] J. W. Console, L. M. Sakata, T. Aung, D. S. Friedman, and M. $\mathrm{He}$, "Quantitative analysis of anterior segment optical coherence tomography images: the Zhongshan Angle Assessment Program," British Journal of Ophthalmology, vol. 92, no. 12, pp. 1612-1616, 2008.

[56] J. L. S. See, P. T. K. Chew, S. D. Smith et al., "Changes in anterior segment morphology in response to illumination and after laser iridotomy in Asian eyes: an anterior segment OCT study," British Journal of Ophthalmology, vol. 91, no. 11, pp. 14851489, 2007.

[57] K. S. Lee, K. R. Sung, S. Y. Kang, J. W. Cho, D. Y. Kim, and M. S. Kook, "Residual anterior chamber angle closure in narrowangle eyes following laser peripheral iridotomy: anterior segment optical coherence tomography quantitative study," Japanese Journal of Ophthalmology, vol. 55, no. 3, pp. 213-219, 2011.

[58] A. Narayanaswamy, L. M. Sakata, M.-G. He et al., "Diagnostic performance of anterior chamber angle measurements for detecting eyes with narrow angles: an anterior segment OCT study," Archives of Ophthalmology, vol. 128, no. 10, pp. 1321-1327, 2010.

[59] C. Y. L. Cheung, S. Liu, R. N. Weinreb et al., "Dynamic analysis of iris configuration with anterior segment optical coherence tomography," Investigative Ophthalmology and Visual Science, vol. 51, no. 8, pp. 4040-4046, 2010. 
[60] P. X. Wang, V. T. C. Koh, and L. S. Chee, "Laser iridotomy and the corneal endothelium: a systemic review," Acta Ophthalmologica, vol. 92, no. 7, pp. 604-616, 2014.

[61] G. Savini, M. Zanini, and P. Barboni, "Filtering blebs imaging by optical coherence tomography," Clinical and Experimental Ophthalmology, vol. 33, no. 5, pp. 483-489, 2005.

[62] N. Nakano, M. Hangai, H. Nakanishi et al., "Early trabeculectomy bleb walls on anterior-segment optical coherence tomography," Graefe's Archive for Clinical and Experimental Ophthalmology, vol. 248, no. 8, pp. 1173-1182, 2010.

[63] A. Tominaga, A. Miki, Y. Yamazaki, K. Matsushita, and Y. Otori, "The assessment of the filtering bleb function with anterior segment optical coherence tomography," Journal of Glaucoma, vol. 19, no. 8, pp. 551-555, 2010.

[64] L. Pfenninger, F. Schneider, and J. Funk, "Internal reflectivity of filtering blebs versus intraocular pressure in patients with recent trabeculectomy," Investigative Ophthalmology and Visual Science, vol. 52, no. 5, pp. 2450-2455, 2011.

[65] K. I. Jung, S. A. Lim, H.-Y. L. Park, and C. K. Park, "Visualization of blebs using anterior-segment optical coherence tomography after glaucoma drainage implant surgery," Ophthalmology, vol. 120, no. 5, pp. 978-983, 2013.

[66] T. Inoue, R. Matsumura, U. Kuroda, K.-I. Nakashima, T. Kawaji, and H. Tanihara, "Precise identification of filtration openings on the scleral flap by three-dimensional anterior segment optical coherence tomography," Investigative Ophthalmology and Visual Science, vol. 53, no. 13, pp. 8288-8294, 2012.

[67] R. Guthoff, T. Guthoff, D. Hensler, F. Grehn, and T. Klink, "Bleb needling in encapsulated filtering blebs: evaluation by optical coherence tomography," Ophthalmologica, vol. 224, no. 4, pp. 204-208, 2010.

[68] C. C. A. Sng, M. Singh, P. T. K. Chew et al., "Quantitative assessment of changes in trabeculectomy blebs after laser suture lysis using anterior segment coherence tomography," Journal of Glaucoma, vol. 21, no. 5, pp. 313-317, 2012.

[69] W. K. Kim, G. J. Seong, C. S. Lee, Y. G. Kim, and C. Y. Kim, "Anterior segment optical coherence tomography imaging and histopathologic findings of an overhanging filtering bleb," Eye (Lond), vol. 22, no. 12, pp. 1520-1521, 2008.

[70] E. Golez III and M. Latina, "The use of anterior segment imaging after trabeculectomy," Seminars in Ophthalmology, vol. 27, pp. 155-159, 2012. 


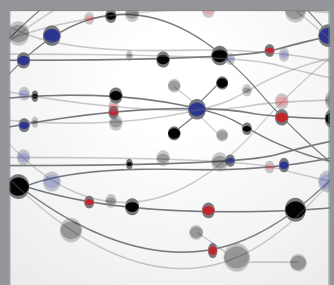

The Scientific World Journal
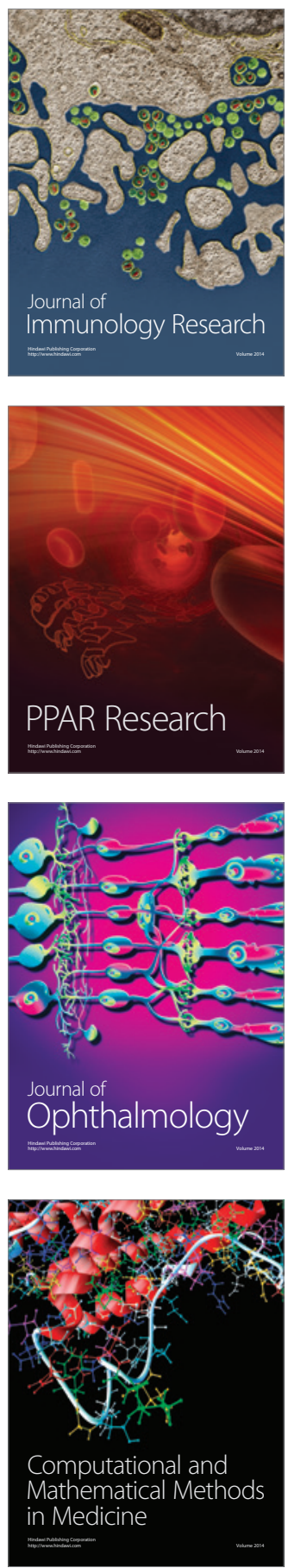

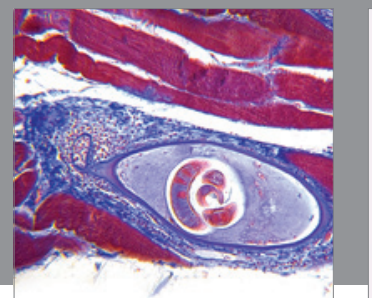

Gastroenterology

Research and Practice
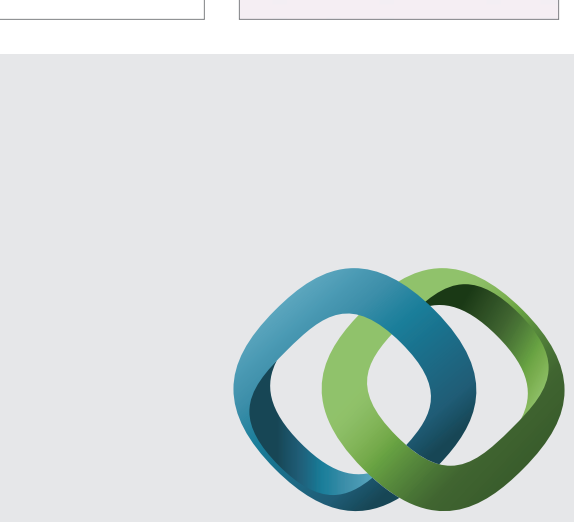

\section{Hindawi}

Submit your manuscripts at

http://www.hindawi.com
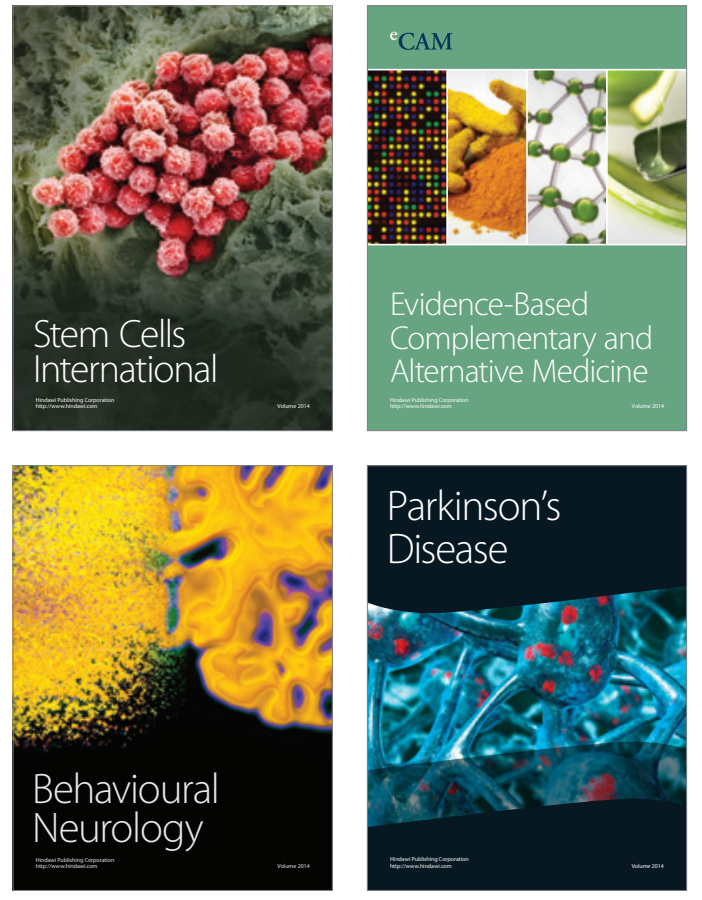
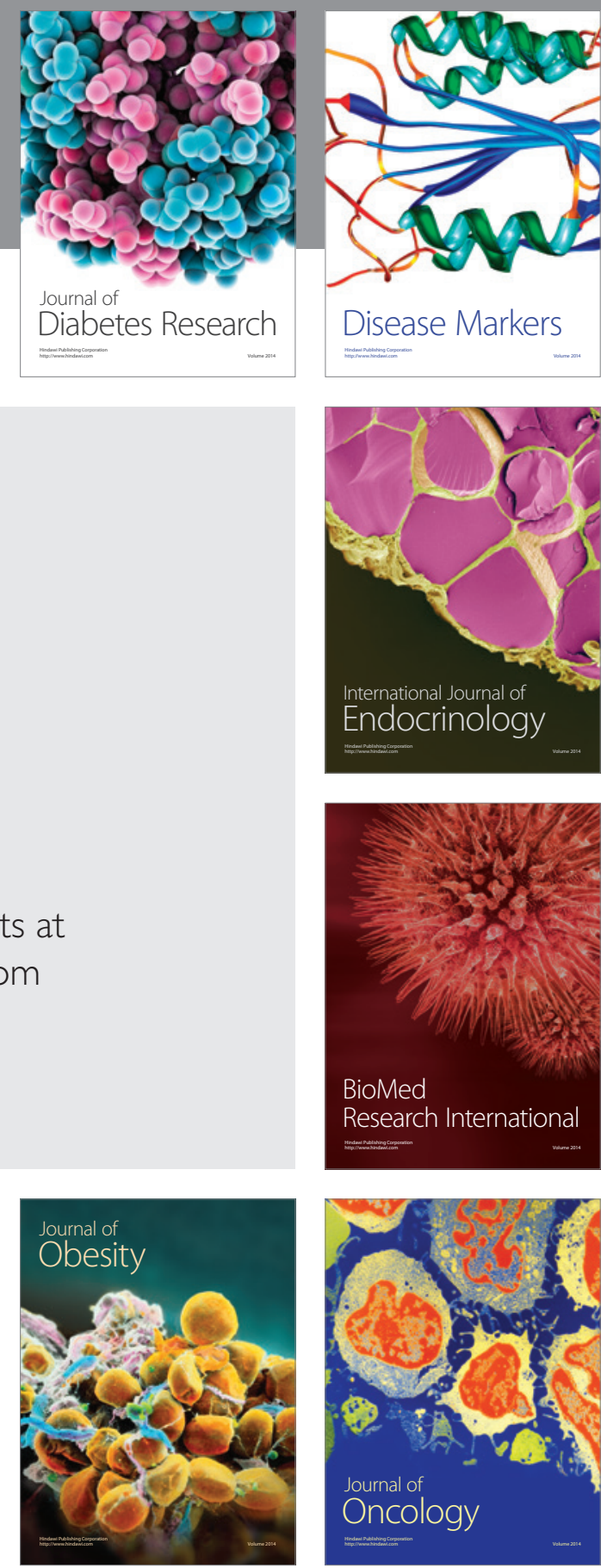

Disease Markers
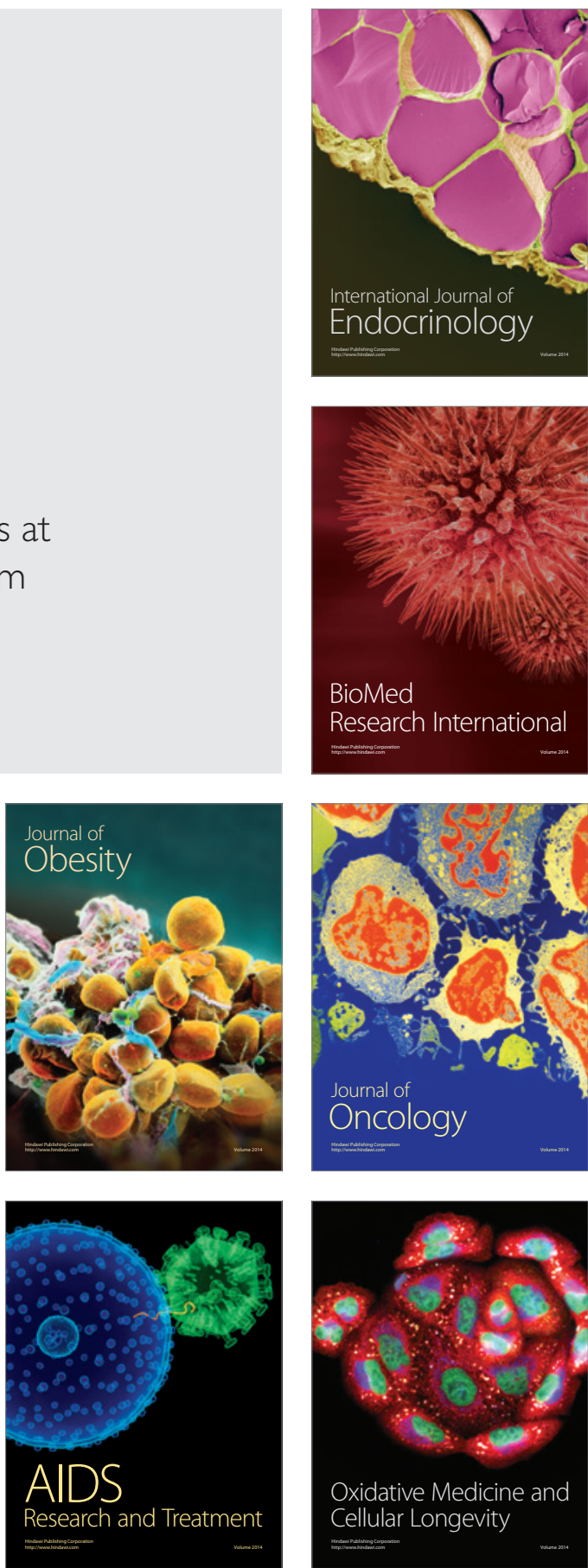